\title{
Early drug eluting stent
} thrombosis in acute coronary syndromes

Plaque rupture and thrombus formation play a key role in the pathogenesis of acute coronary syndrome (ACS) [1]. The etiology of early stent thrombosis (ST) (within 30 days) after stent implantation is multifactorial. Clinical studies implicate multiple factors comprising clinical demographics such as diabetes mellitus, renal failure, angiographic lesion characteristics (greater burden of coronary atherosclerosis), interventional procedure-related factors (smaller final stent minimal lumen diameter) and pharmacotherapeutic conditions (preprocedural inconsistent antiplatelet drug use) as predictors of early ST [2,3]. The discontinuation of dual antiplatelet therapy was a powerful predictor of ST during the first 6 months following stent implantation in a cohort of over 3,000 patients (HR 13.74; 95\% CI 4.04-46.68; $\mathrm{P}<0.001$ ) [4]. This was confirmed by a study by Schulz et al. in over 6,000 patients with 4-years follow up [5].

Intravascular ultrasound (IVUS) has been the standard imaging modality for evaluating the status of a coronary stent. However, it is limited in evaluating neointimal tissue within the stented segment due to its low resolution. Contrary to IVUS, optical coherence tomography (OCT) has a resolution of 10-20 $\mu \mathrm{m}$, which is about 10 times higher than that of IVUS $(80-120 \mu \mathrm{m})$. Previous studies have shown the superiority of OCT over IVUS in relation to resolution capacity [6]. Currently different types of stent related vessel damage can be clearly identified with help of OCT as shown in Table 1.

\section{Table 1: Quantitative OCT parameters for suboptimal stent deployment.}

\begin{tabular}{|c|c|}
\hline Parameter & Definition \\
\hline Edge dissection & $\begin{array}{l}\text { Presence of a linear rim of tissue with a maximal width } \geq 200 \mu \mathrm{m} \text { and a clear } \\
\text { separation from the vessel wall or underlying plaque that was adjacent }(<5 \\
\mathrm{mm}) \text { to a stent edge }[7,8] \text {. }\end{array}$ \\
\hline Reference lumen narrowing & $\begin{array}{l}\text { Lumen area }<4.5 \mathrm{~mm}^{2} \text { in the presence of significant residual plaque } \\
\text { adjacent to stent edges [8]. }\end{array}$ \\
\hline Stent Strut Malapposition & Distance from Stent strut to adjacent vessel wall >200 $\mu \mathrm{m}$ (Figure 1) [8-10]. \\
\hline Residual stenosis & In-stent minimum lumen area $<70 \%$ of the average reference lumen area [8]. \\
\hline $\begin{array}{l}\text { Intrastent plaque/thrombus } \\
\text { protrusion }\end{array}$ & $\begin{array}{l}\text { Plaque/thrombus prolapsing between stent struts into the vessel lumen } \\
\geq 500 \mu \mathrm{m} \text { in thickness (Figure 2) }[7,9,11,12] \text {. }\end{array}$ \\
\hline intra-stent dissection flaps & $\begin{array}{l}\text { Defined as a disruption of the luminal vessel surface in the stent segment } \\
\text { with a dissection flap protruding in the lumen. Significant if dissection } \\
\text { flap tip to the joint point with the vessel wall extending } \geq 200 \mu \mathrm{m} \text { into the } \\
\text { lumen (Figure 3) [13]. }\end{array}$ \\
\hline intra-s & $\begin{array}{l}\text { Defined as a disruption of the luminal vessel surface in the stented segment } \\
\text { with an underlying cavity in the vessel wall [13]. }\end{array}$ \\
\hline Tissue prolapse & $\begin{array}{l}\text { Defined as convex-shaped tissue with a regular surface protruding } \\
\text { between adjacent stent struts towards the lumen, without disruption of } \\
\text { the continuity of the luminal vessel surface. The maximal prolapse of tissue } \\
\text { was measured and was defined as the distance from the arc connecting } \\
\text { adjacent stent struts to the greatest extent of prolapse into the lumen (TP } \\
\text { length) } \geq 200 \mu \mathrm{m} \text { in the lumen [14]. }\end{array}$ \\
\hline Red & $\begin{array}{l}\text { Defined as an intraluminal mass discontinuing of the surface of the vessel } \\
\text { wall with a signal free shadow behind the structure [15]. }\end{array}$ \\
\hline
\end{tabular}

Alaa Solaiman Algazzar*, Ahmed Abd ElMoez ElSayed, Azza Ali Katta, Khaled S.

Ahmed

National Heart Institute, Egypt

*Author for correspondence:

Tel.: 01148145561

goodminds@hotmail.com

Submitted: January 12, 2018

Accepted: February 05, 2018

Published online: February 12, 2018 
Previous IVUS studies in patients with mostly stable angina have reported small stent [7-15], underexpansion, stent edge dissection, and residual reference segment disease as the strongest IVUS predictors of ST [16-18]. In the IVUS sub study from the HORIZONS-AMI trial, the 2 strongest predictors of definite/probable early ST were the minimum lumen cross sectional area because of tissue protrusion after stenting and inflow/ outflow disease (residual stenosis or dissection) as well as a higher incidence of TIMI grade 0 / flow at baseline and after stenting [19].

An autopsy registry investigated the histopathology features of early (ST) in 67 stented coronary lesions from 59 patients who presented with acute coronary syndrome (ACS) and died within 30 days. The investigator found that prolapse of necrotic core (NC) was significantly greater in thrombosed compared to patent lesions ( $70 \%$ vs. $43 \%, \mathrm{p}=0.045$ ); plaque rupture as precedent of ACS was significantly greater in sections with thrombosis compared to patent sections; and the extent of NC prolapse, medial tear, and incomplete strut apposition were significantly greater in thrombosed compared to patent sections [20].

In CLI-OPCI ACS Sub study, stent malapposition $(>200 \mu \mathrm{m})$ in the acute setting, was not associated to a worse outcome. Device oriented cardiovascular events (DoCE) rate was very similar in patients with or without OCT-detected acute stent malapposition (ASM) (12.8\% vs.11.4\%; $\mathrm{P}=0.730)$. Unlike previous findings in the stable setting, significant residual intrastent plaque/thrombus protrusion after PCI was associated with an increased risk of DoCE recurrence at followup in ACS patients [21]. These results confirmed the previous IVUS and OCT findings failed to relate acute stent-vessel wall malapposition with clinical outcome (Figure 1) [22,23].

IVUS analysis of TAXUS IV, $\mathrm{V}$ and $\mathrm{VI}$ and TAXUS ATLAS Workhorse, Long Lesion and Direct Stent studies showed that routinely detected ASM in bare metal stent (BMS) or TAXUS patients was not associated with early- and long-term adverse clinical events, in particular any early or late stent thrombosis [24]. However, late stent malapposition may be the consequence of chronic inflammation and delayed healing, resulting in tissue necrosis and erosion around the stent. It is suggested that delayed reendothelialization, impaired vasomotion and chronic inflammation, allow for platelet adhesion, initiation of the coagulation cascade and subsequent thrombotic stent occlusion [25].

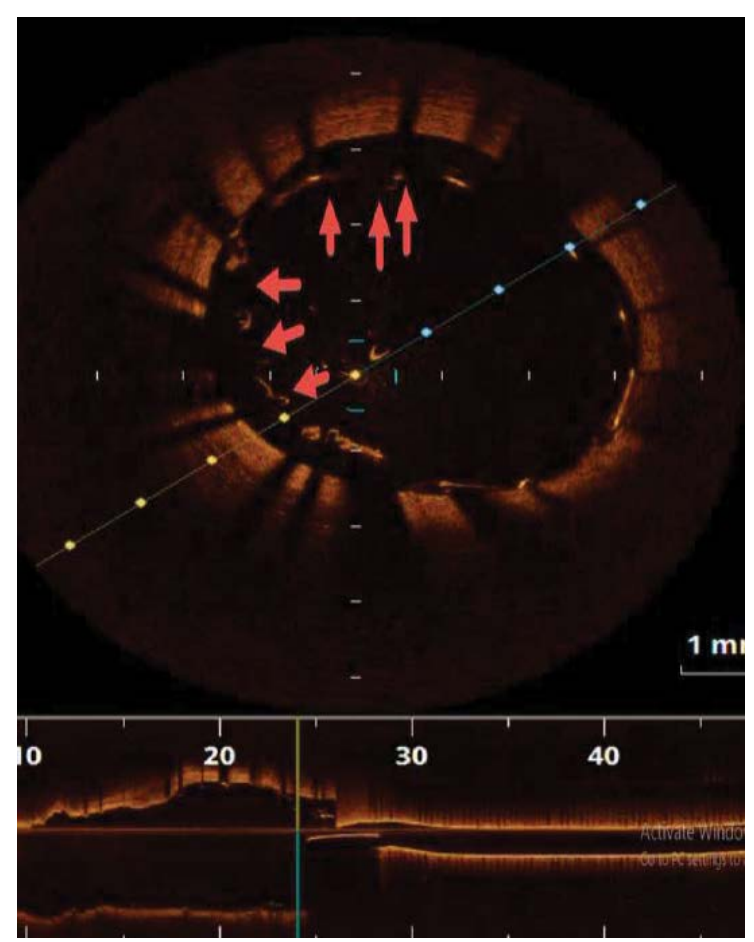

Figure 1: Stent Strut Malapposition. Look for space between Stent strut to adjacent vessel wall (red arrows).

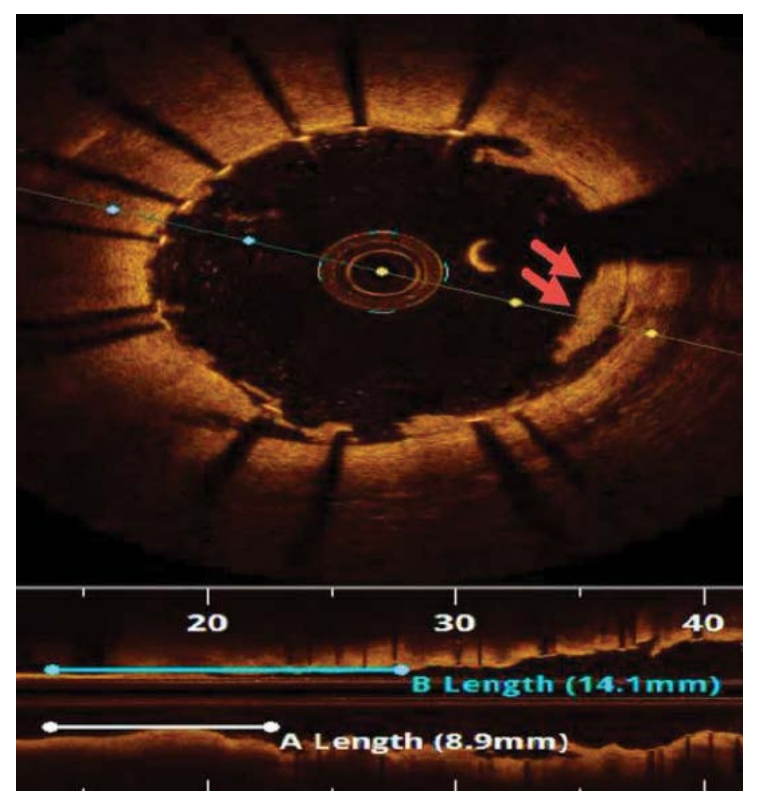

Figure 2: Intrastent plaque/thrombus protrusion through stent struts (red arrows).

Another hidden cause of acute stent thrombosis is Intra-stent dissection which is disruption of the luminal vessel surface in the stent segment. It can appear in two forms: (a) dissection: the vessel surface is disrupted and a dissection flap is visible; (b) cavity: the vessel surface is disrupted and an empty cavity can be seen. The pathophysiology of Intra-stent dissection is speculative 


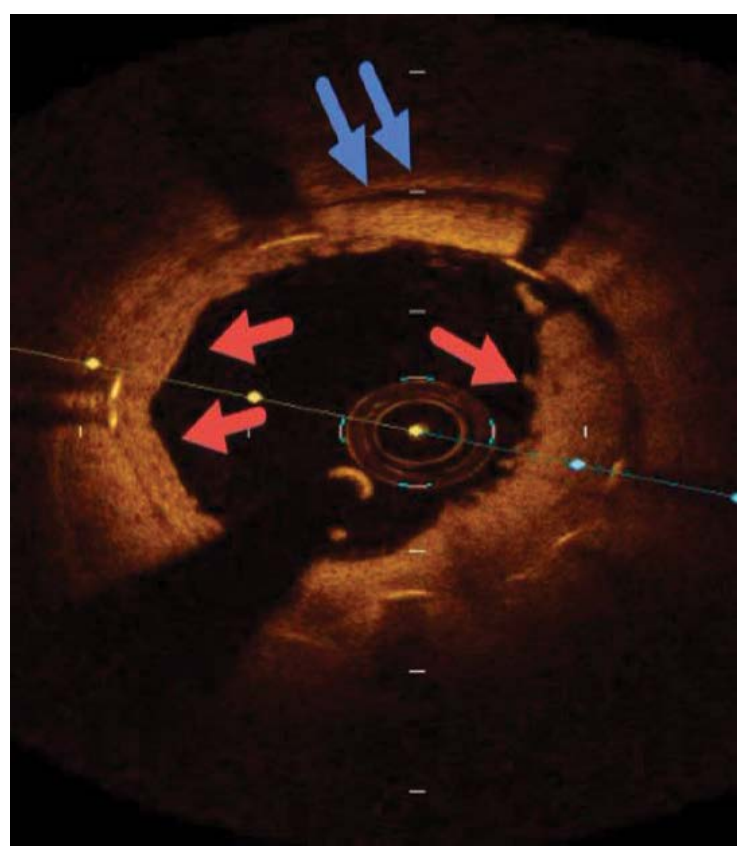

Figure 3: Intrastent dissection (blue arrows) and acute intraluminal stent thrombus red arrow.

\section{References}

1. Virmani R, Burke AP, Farb A, Kolodgie FD. Pathology of the vulnerable plaque. J. Am. Coll. Cardiol. 47(8): C13-C18 (2006).

2. Aoki J, Lansky AJ, Mehran R, et al. Early stent thrombosis in patients with acute coronary syndromes treated with drugeluting and bare metal stents: the Acute Catheterization and Urgent Intervention Triage Strategy trial. Circulation. 119: 687-698 (2009).

3. Dangas GD, Claessen BE, Mehran R, et al. Development and validation of a stent thrombosis risk score in patients with acute coronary syndromes. J. Am. Coll. Cardiol. Intv. 5: 1097-1105 (2012).

4. Airoldi F, Colombo A, Morici N, et al. Incidence and predictors of drug-eluting stent thrombosis during and after discontinuation of thienopyridine treatment. Circulation. 116 (7): 745-754 (2007)

5. Schulz S, Schuster T, Mehilli J, et al. Stent thrombosis after drugeluting stent implantation: incidence, timing, and relation to discontinuation of clopidogrel therapy over a 4-year period. Eur. Heart. J. 30(22): 2714-2721 (2009).

6. Suzuki Y, Ikeno F, Koizumi T, et al. In vivo comparison between optical coherence tomography and in-travascular ultrasound for detecting small degrees of in-stent neo-intima after stent implantation. JACC. Cardiovasc. Interv. 1: 168-173 (2008).

7. Prati F, Guagliumi G, Mintz GS, et al. Expert's OCT Review Document. Expert review document part 2: methodology, terminology and clinical applications of optical coherence tomography for the assessment of interventional procedures. Eur. Heart. J. 33: 2513-2520 (2012).

8. Imola F, Mallus MT, Ramazzotti V, et al. Safety and feasibility of frequency domain optical coherence tomography to guide but likely involves rupture of new plaque within the stent, with propagation of the dissection plane along the interface between the stent and intima. Assessment of OCT in some studies has revealed that vessel wall injury (tissue prolapse $97.5 \%$, intra-stent dissection flap $86.3 \%$, edge dissection $25.0 \%$ ) after DES deployment occurs more frequently than previously expected $[13,26]$. However, most of these injuries heal at 9-month follow up period [14].The use of OCT in percutaneous coronary procedures represents a step ahead for understanding atherosclerotic disease and the response of the intima to stent placement. decision making in percutaneous coronary intervention. EuroInterven. 6: 575-581 (2010).

9. Tanigawa J, Barlis P, Di Mario C. Intravascular optical coherence tomography: optimisation of image acquisition and quantitative assessment of stent strut apposition. EuroInterven. 3: 128-136 (2007).

10. Serruys PW, Onuma Y, Ormiston JA, et al. Evaluation of the second generation of a bioresorbable everolimus drug-eluting vascular scaffold for treatment of de novo coronary artery stenosis: six-month clinical and imaging outcomes. Circulation. 122: 2301-2312 (2010)

11. Kume T, Akasaka T, Kawamoto T, et al. Assessment of coronary arterial thrombus by optical coherence tomography. Am. J. Cardiol. 97: 1713-1717 (2006).

12. Prati F, Romagnoli E, Burzotta F, et al. Clinical impact of OCT findings during PCI: the CLI-OPCI II study. JACC. Cardiovasc. Imaging. 8: 1297-1305 (2015).

13. Gonzalo N, Serruys PW, Okamura T, et al. Optical coherence tomography assessment of the acute effects of stent implantation on the vessel wall: a systematic quantitative approach. Heart. 95: 1913-1919 (2009).

14. Dries DC, Johan B, Giovanni JU, et al. Healing course of acute vessel wall injury after drug-eluting stent implantation assessed by optical coherence tomography. Euro. Heart. J. 15: 800-809 (2014).

15. Radu M, Raber L, Kalesan B, et al. Coronary evaginations are associated with positive vessel remodelling and are nearly absent following implantation of newer-generation drug-eluting stents: an optical coherence tomography and intravascular ultrasound study. Eur. Heart. J. 35: 795-807 (2014). 
16. Alfonso F, Sua'rez A, Angiolillo DJ, et al. Findings of intravascular ultrasound during acute stent Thrombosis. Heart. 90: 1455-1459 (2004).

17. Fujii K, Carlier SG, Mintz GS, et al. Stent underexpansion and residual reference segment stenosis are related to stent thrombosis after sirolimus-eluting stent implantation an intravascular ultrasound study. J. Am. Coll. Cardiol. 45: 995-998 (2005).

18. Liu X, Doi H, Maehara A, et al. Volumetric intravascular ultrasound comparison of early drug-eluting stents thrombosis versus drug-eluting stent restenosis. J. Am. Coll. Cardiol. Cardiovasc. Interv. 2: 428-434 (2009).

19. Choi SY, Witzenbichler B, Maehara A, et al. Intravascular ultrasound findings of early stent thrombosis after primary percutaneous intervention in acute myocardial infarction: a Harmonizing Outcomes with Revascularization and Stents in Acute Myocardial Infarction (HORIZONS-AMI) substudy. Circ. Cardiovasc. Interv. 4: 239-247 (2011).

20. Nakano M, Yahagi K, Otsuka F, et al. Causes of early stent thrombosis in patients presenting with acute coronary syndrome: an ex vivo human autopsy study. J. Am. Coll. Cardiol. 63(23): 2510-2520 (2014).

21. Prati F, Romagnoli E, Gatto L, et al. Clinical Impact of
Suboptimal Stenting and Residual Intrastent Plaque/Thrombus Protrusion in Patients With Acute Coronary Syndrome The CLI-OPCI ACS Substudy. Circ. Cardiovasc. Interv. 9: e003726 (2016).

22. Soeda T, Uemura S, Park SJ, et al. Incidence and clinical significance of poststent optical coherence tomography findings: one-year follow-up study from a multicenter registry. Circulation. 132: $1020-1029$ (2015).

23. Di Giorgio A, Capodanno D, Ramazzotti V, et al. Optical coherence tomography guided in-stent thrombus removal in patients with acute coronary syndromes. Int. J. Cardiovasc. Imaging. 29: 989-996 (2013).

24. Steinberg DH, Mintz GS, Mandinov L, et al. Long-term impact of routinely detected early and late incomplete stent apposition: an integrated intravascular ultrasound analysis of the TAXUS IV, $\mathrm{V}$, and VI and TAXUS ATLAS workhorse, long lesion, and direct stent studies. JACC. Cardiovasc. Interv. 3: 486-494 (2010).

25. Cook S, Wenaweser $\mathrm{P}$, Togni $\mathrm{M}$, et al. Incomplete stent apposition and very late stent thrombosis after drug-eluting stent implantation. Circulation. 115: 2426-2434 (2007).

26. Bouma BE, Tearney G, Yabushita H, et al. Evaluation of intracoronary stenting by intravascular optical coherence tomography. Heart. 89: 317-320 (2003). 